\title{
Evaluation of Subependymal Gray Matter Heterotopias on Fetal MRI
}

\author{
(D) U.D. Nagaraj, (D).L. Peiro, (DK.S. Bierbrauer, and (D)B.M. Kline-Fath
}

\begin{abstract}
BACKGROUND AND PURPOSE: Subependymal grey matter heterotopias are seen in a high proportion of children with Chiari II malformation and are potentially clinically relevant. However, despite its growing use, there is little in the literature describing its detection on fetal MRI. Our aim was to evaluate the accuracy in diagnosing subependymal gray matter heterotopias in fetuses with spinal dysraphism on fetal MR imaging.
\end{abstract}

MATERIALS AND METHODS: This study is a retrospective analysis of 203 fetal MRIs performed at a single institution for spinal dysraphism during a 10-year period. Corresponding obstetric sonography, postnatal imaging, and clinical/operative reports were reviewed.

RESULTS: Of the fetal MRIs reviewed, 95 fetuses were included in our analysis; $23.2 \%$ (22/95) were suspected of having subependymal gray matter heterotopias on fetal MR imaging prospectively. However, only $50 \%$ (11/22) of these cases were confirmed on postnatal brain MR imaging. On postnatal brain MR imaging, 28.4\% (27/95) demonstrated imaging findings consistent with subependymal gray matter heterotopia. Only $40.7 \%$ (11/27) of these cases were prospectively diagnosed on fetal MR imaging.

CONCLUSIONS: Fetal MR imaging is limited in its ability to identify subependymal gray matter heterotopias in fetuses with spinal dysraphism. It is believed that this limitation relates to a combination of factors, including artifacts from fetal motion, the very small size of fetal neuroanatomy, differences in imaging techniques, and, possibly, irregularity related to denudation of the ependyma/subependyma in the presence of spinal dysraphism and/or stretching of the germinal matrix in ventriculomegaly.

ABBREVIATIONS: $\mathrm{GA}=$ gestational age; $\mathrm{SEH}=$ subependymal gray matter heterotopias; $\mathrm{VMG}=$ ventriculomegaly

$F^{\prime}$ tal MR imaging plays an important role in the evaluation of fetuses with suspected central nervous system abnormalities; the indications for, availability of, and the use of fetal MRI are increasing. ${ }^{1-3}$ The role of fetal MR imaging is important in the evaluation of spinal dysraphisms and is vital in the assessment for prenatal repair of myelomeningoceles. Because the Management of Myelomeningocele randomized controlled trial has shown that prenatal surgery for myelomeningoceles reduces the need for shunting and may improve neurologic function in some patients,

Received July 15, 2015; accepted after revision September 8.

From the Departments of Radiology and Medical Imaging (U.D.N., B.M.K.-F), Pediatric Surgery (J.L.P.), and Pediatric Neurosurgery (K.S.B.), Cincinnati Children's Hospital Medical Center, Cincinnati, Ohio; and University of Cincinnati College of Medicine (U.D.N., J.L.P., K.S.B., B.M.K.-F), Cincinnati, Ohio.

Preliminary results were previously presented at: American Society of Neuroradiology Annual Meeting and the Foundation of the ASNR Symposium; April 25-30, 2015; Chicago, Illinois; No. O-176.

Please address correspondence to Usha D. Nagaraj, MD, Department of Radiology and Medical Imaging, Cincinnati Children's Hospital Medical Center, 3333 Burnet Ave, Cincinnati, OH 45229-3026; e-mail: usha.nagaraj@cchmc.org; @CincyRadKids

http://dx.doi.org/10.3174/ajnr.A4585
MR imaging has become imperative in evaluating these fetuses before intervention. ${ }^{4-6}$

Subependymal gray matter heterotopias $(\mathrm{SEH})$ are seen in a relatively high proportion of children with Chiari II malformation, with a reported incidence as high as $30 \%{ }^{7}$ Although the exact implications in this subset of patients are still under investigation, ample reports in the literature describe the clinical relevance of SEH. ${ }^{8-12} \mathrm{Up}$ to $80 \%$ of patients with SEH have been reported to develop epilepsy during their lifetimes, and disorders of cognition are seen in anywhere from $20 \%$ to $60 \%$. $^{9}$ The presence of SEH also demonstrates a strong association with other structural anomalies in the brain in addition to Chiari malformation, including cerebral cortical malformations, callosal anomalies, and decreased white matter volume. ${ }^{10-12}$ However, very little radiology literature has reported on the detection of SEH on fetal MR imaging, with only case reports and a few small case series described. ${ }^{13-15}$ Many authors believe that SEH can be identified on fetal MR imaging. ${ }^{3,16,17}$ In 1 small series of 15 patients, fetal MR imaging was reported to be up to $100 \%$ specific, though only $67 \%$ sensitive, in detecting SEH. ${ }^{17}$ To date, no large series have 


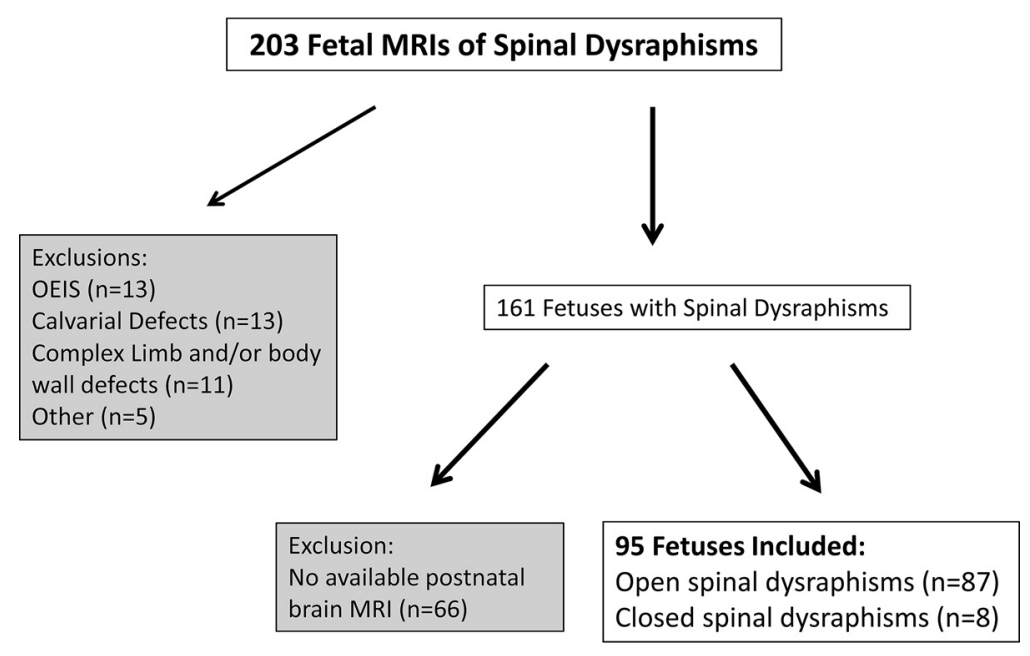

FIG 1. Breakdown of the fetuses included in our study. OEIS indicates omphalocele-exstrophyimperforate anus-spinal defects.

examined this finding on MR imaging in fetuses with spinal dysraphism.

The purpose of this study was to examine the accuracy of diagnosing SEH in fetuses with spinal dysraphism via fetal MR imaging.

\section{MATERIALS AND METHODS \\ Study Design}

This study was a single-center, retrospective chart review. Illuminate InSight software (Softek Solutions, Prairie Village, Kansas), a program utilized for data aggregation and search engine functions, was used to compile a list of fetuses with open and closed spinal dysraphisms imaged via fetal MR imaging at Cincinnati Children's Hospital Medical Center in Cincinnati, Ohio, between 2004 and 2014. Additional cases of spinal dysraphism were also obtained from a radiology fetal case list. Only patients with available postnatal brain MRIs were included in this analysis. Patients with omphalocele-exstrophy-imperforate anus-spinal defects complex or complicating limb, body wall, or calvarial defects (anencephaly, encephaloceles) were excluded. The images were viewed in the PACS. A chart review was performed to obtain relevant clinical data. This study was Health Insurance Portability and Accountability Actcompliant and was approved by the institutional review board. The requirement for informed consent was waived.

\section{Imaging Parameters}

All 95 fetuses included in our analysis were scanned prenatally on a 1.5T magnet within the group of hospitals that are a part of the Fetal Care Center of Cincinnati, with 97.9\% (93/95) of fetal MRIs performed at Cincinnati Children's Hospital Medical Center on either a GE Signa (Milwaukee, Wisconsin) or a Phillips Ingenia (Best, the Netherlands) system. Only diagnostic-quality MRIs for the assessment of the fetal brain were included in our study, and this was a subjective assessment made by the radiologists. T2 single-shot fast spin-echo images of the brain were the most useful in identifying SEH and were obtained in 3 planes: axial, sagittal, and coronal. Section thicknesses of 3-mm, no gap, interleaved images at $\leq 24$ weeks' gestational age (GA) and $4-\mathrm{mm}$, no gap, interleaved images at $>24$ weeks GA were used. Although this imaging protocol did not change during the study period, the TR and TE varied among scanners and were changed at times of scanner upgrades to optimize image quality. At least 2 stacks in each plane were obtained to the radiologist's satisfaction. The smallest FOV possible was used. T1WI of the fetal brain and body were obtained; however, they were not useful in identifying additional SEH. Axial DWI of the fetal brain was inconsistently implemented at the radiologist's discretion and was not helpful in identifying additional SEH in any of the cases. Images were reviewed for the presence or absence of $\geq 1$ subependymal gray matter heterotropia identified in at least 2 planes.

All 95 patients included in our analysis had diagnostic-quality postnatal brain MRIs available for interpretation, as determined by the radiologists. The postnatal imaging parameters varied because 1 of 6 clinical magnets was used and the routine use of $\mathrm{T} 13 \mathrm{D}$ spoiled gradient-recalled imaging was not implemented until 2009. We found that SEH were best identified on axial T2 FSE sequences postnatally, though sagittal T1WI was helpful as well in certain cases.

\section{Image Interpretation}

All images were reviewed by 2 board-certified radiologists (U.D.N., B.M.K.-F.), both with added qualifications in pediatric radiology and fellowship training in pediatric neuroradiology, 1 (B.M.K.-F) with $>10$ years of postfellowship attending experience in pediatric neuroradiology in a large academic center. The readers were blinded to the pre- and postnatal imaging findings at the time of interpretation. Differences were resolved by consensus.

\section{Statistical Analysis}

Statistical analysis was performed by using Excel (Microsoft, Redmond, Washington) 2013 spreadsheet mathematic functions, including average values, SDs, value count, and Student $t$ test.

\section{RESULTS}

\section{Description of Our Cohort}

Of the 203 MRIs of fetuses with spinal dysraphism reviewed, 161 fetuses were identified as having spinal dysraphism without evidence of omphalocele-exstrophy-imperforate anus-spinal defects complex or complicating limb, body wall, or calvarial defects. In this cohort, 95 fetuses had postnatal brain MRIs available for interpretation and were included in our analysis (Fig 1); 37.9\% (36/95) of these fetuses were male. The average gestational age at MR imaging was $24.23 \pm$ 3.9 weeks; $22.1 \%$ (21/95) of these patients underwent open fetal surgery for in utero repair of a myelomeningocele. The average age at postnatal brain MR imaging was $58.8 \pm 159.7$ days.

In total, $91.6 \%(87 / 95)$ had open spinal dysraphism, while the remaining were closed; $91.6 \%$ (87/95) had evidence of Chiari II malformation in the posterior cranial fossa; and of those with a normal posterior fossa, $50 \%(4 / 8)$ had closed spinal dysraphisms. Of the 

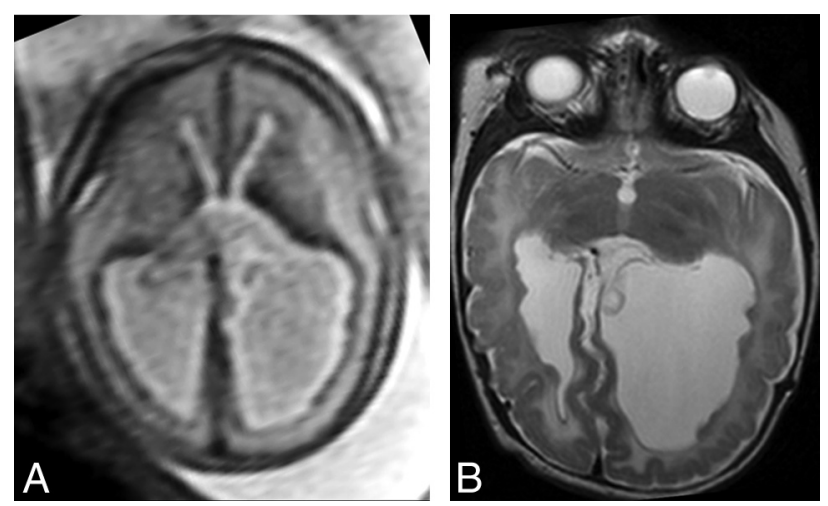

FIG 2. Example of SEH prospectively diagnosed on fetal MR imaging (true-positive finding). Axial T2 single-shot fast spin-echo imaging of the fetal brain at 25 weeks' GA $(A)$ demonstrates multiple nodules along the ependymal surfaces of the lateral ventricles suspicious for SEH. Postnatal brain MR imaging at 5 weeks of age $(B)$ confirms the presence of bilateral SEH on axial T2 FSE.

open spinal dysraphisms, 74.7\% (65/87) had myelomeningoceles, while the remaining $25.3 \%$ (22/87) had myeloceles, defined as a neural placode flush with the skin surface. ${ }^{18}$ Eighty percent $(76 / 95)$ of patients had significant ventriculomegaly (VMG) on fetal MR imaging, defined as the atria of the lateral ventricles measuring $\geq 10 \mathrm{~mm}$ in transverse diameter. This measurement was obtained in the axial plane at the level of the frontal horns or in the coronal plane at the level of the glomoid of the choroid plexus, analogous to previously established fetal sonography guidelines. ${ }^{19}$

\section{Imaging Findings}

In total, $23.2 \%$ (22/95) of the fetuses studied were suspected of having SEH on fetal MR imaging. The average GA of this group of patients at imaging was $25.47 \pm 4.9$ weeks. Of these fetuses, $50 \%$ $(11 / 22)$ were confirmed as having at least 1 subependymal gray matter heterotopia on postnatal brain MR imaging (Fig 2). All 22 of these cases had VMG on fetal MR imaging. The average GA of the postnatally confirmed patients was $24.7 \pm 4.7$ weeks, while the average GA of the 11 patients that did not demonstrate SEH postnatally was $26.2 \pm 5.3$ weeks, a difference that was not statistically significant $(P=.49)$.

The fetal MRIs of the examinations with false-positive findings were re-examined. Of the 11 fetuses in which SEH were initially noted on fetal MR imaging but not confirmed on postnatal brain MR imaging (false-positives), all 11 demonstrated identifiable areas of nodularity along the ependymal surfaces of the lateral ventricles on fetal MR imaging (Fig 3). The MRIs of the 11 fetuses with true-positive findings were also re-examined, and it was confirmed that SEH identified on the postnatal examination corresponded to ependymal nodularity in the same locations on fetal MR imaging in all 11 patients. However, 18.2\% (2/11) of the fetuses with true-positive findings had additional areas of nodularity identified on fetal MR imaging that did not correspond to SEH on the postnatal examination.

On postnatal brain MR imaging, 28.4\% (27/95) of patients demonstrated imaging findings consistent with SEH; $40.7 \%$ $(11 / 27)$ of these patients were prospectively diagnosed on fetal MR imaging (true-positives). Of these, 70.4\% (19/27) of neonates had $\geq 3$ heterotopias identified postnatally, with $52.6 \%$
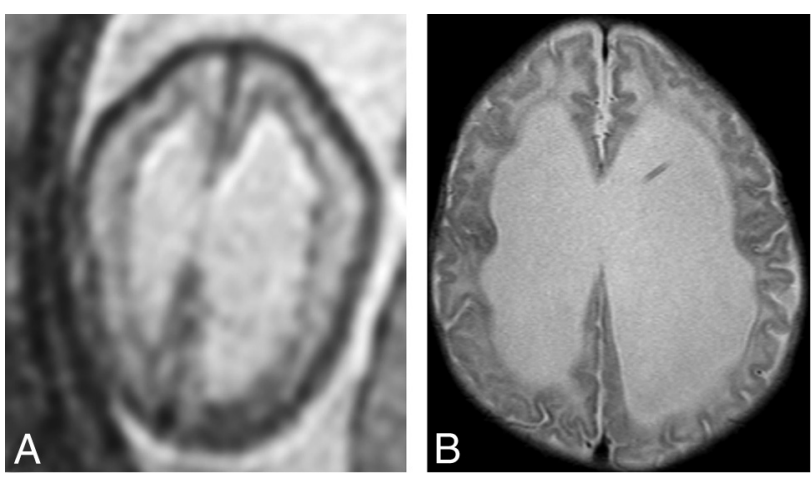

FIG 3. An example of subependymal nodularity giving the false appearance of SEH (false-positive finding). Axial T2 single-shot fast spinecho image from fetal MR imaging at 24 weeks' GA ( $A$ ) demonstrates nodularity along the ependymal surfaces of the lateral ventricles, giving the appearance of SEH. However, postnatal MR imaging at 8 weeks of age $(B)$ does not demonstrate any SEH.

(10/19) being identified prospectively on fetal MR imaging. On the other hand, $29.6 \%(8 / 27)$ had 1-2 heterotopias identified on postnatal examination, with only $12.5 \%(1 / 8)$ identified prospectively on fetal MR imaging. Of the $16 / 27$ fetuses having SEH confirmed postnatally but not identified prenatally (falsenegative findings), $81.3 \%$ (13/16) had VMG on fetal MR imaging. On the other hand, $100 \%(11 / 11)$ of the fetuses with true-positive findings and $100 \%(11 / 11)$ of those with falsepositive findings had VMG on fetal MR imaging. However, the actual mean transverse atrial diameter on fetal MR imaging of those with true-positive findings $(16.6 \pm 4.5 \mathrm{~mm})$ was not significantly different from those with false-positive findings (15.6 $\pm 6.8 \mathrm{~mm}, P=.69$ ) or false-negative findings (16.8 \pm 7.6 $\mathrm{mm}, P=.94)$.

Average GA of the patients with SEH prospectively diagnosed (true-positive findings) was $24.7 \pm 4.7$ weeks, while the average GA of the fetuses with SEH not identified prenatally (false-negative findings) was $23.7 \pm 3.1$ weeks. The difference in GA was not found to be statistically significant $(P=.54)$. To exclude the presence or absence of VMG as a confounding variable, we compared the GAs between only those with true-positive $(n=11,24.7 \pm 4.7$ weeks) and false-negative ( $n=13,24.1 \pm 3.3$ weeks) findings with VMG and found no statistically significant difference $(P=.72)$.

The fetal MRIs with SEH not identified on prenatal imaging but found on postnatal imaging (false-negatives), were also re-examined to determine whether they could be identified in retrospect. Of the 16 fetuses with false-negative findings, we were unable to identify the SEH on fetal MR imaging in $68.8 \%$ $(11 / 16)$, even in retrospect. While $90.9 \%(10 / 11)$ of these cases were believed to have SEH too small to detect on fetal MR imaging, it was thought that fetal motion contributed to the lack of prenatal detection in $9.1 \%(1 / 11)$ of these patients. In the remaining 5 patients, in retrospect, mild nodularity was noted, which may have corresponded to the postnatal findings. However, in 2/5 of these patients, other areas of subependymal nodularity that did not correspond to SEH on postnatal imaging were identified (Fig 4). In addition, in 2/5 patients, the SEH were small on postnatal imaging, measuring as small as $1 \mathrm{~mm}$ and as large as $3 \mathrm{~mm}$ and were likely missed on fetal MR imaging because of their diminutive size. It is believed that in the 

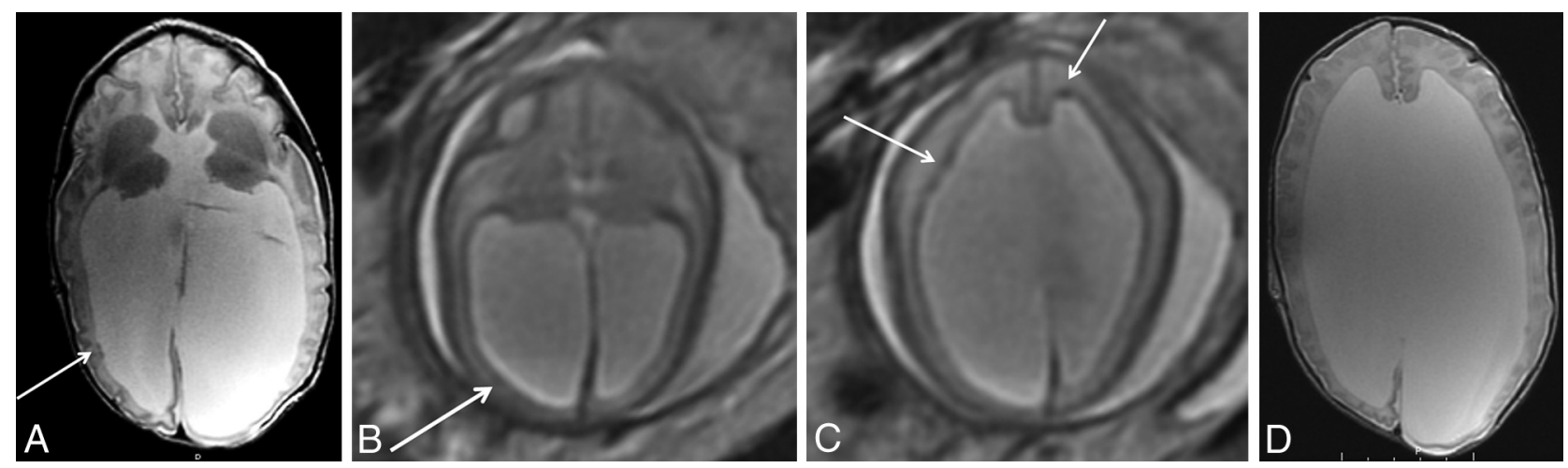

FIG 4. Example of a false-negative finding in a patient with SEH. Postnatal brain MR imaging at 15 days of age (A) demonstrates 2 small SEH along the right lateral ventricle (arrow) on axial T2 FSE imaging. In retrospect, there is some subtle asymmetric irregularity of the subependyma (arrow) on fetal MR imaging at 24 weeks' GA (B) on axial T2 single-shot fast spin-echo imaging. However, other areas of nodularity on fetal MR imaging in this patient (C, arrows) do not correspond to SEH postnatally $(D)$.

remaining $1 / 5$ patients with SEH identified postnatally, the lesion could not be detected prenatally because the location of the heterotopia identified in the right frontal horn was obscured prenatally due to motion artifact in this area.

\section{DISCUSSION}

We examined the accuracy of MR imaging in diagnosing SEH in fetuses with spinal dysraphism by looking at the data from our institution. We demonstrated that in our experience, fetal MR imaging is $40 \%$ sensitive and $50 \%$ specific in the diagnosis of SEH. We demonstrated a higher rate of VMG in cases with true-positive and false-positive findings than in those with false-negative findings. We also demonstrated a higher rate of false-negative findings when $<3$ heterotopias were identified postnatally. GA at the time of imaging did not appear to have a relationship with the sensitivity or specificity of diagnosing SEH.

A number of articles in the literature describe the appearance of SEH on fetal MR imaging. ${ }^{3,14,15,20,21}$ However, very few describe the diagnostic accuracy. ${ }^{17,22}$ The largest published series of 15 patients reported that fetal MR imaging was up to $73 \%$ sensitive and $100 \%$ specific for diagnosing SEH. ${ }^{17}$ Our study examined a much larger cohort of patients, increasing the validity of our findings. However, we focused on a specific population of patients, looking only at fetuses with prenatally diagnosed spinal dysraphisms; this type of search decreased the generalizability of our findings.

The relatively low sensitivity for detecting SEH on fetal MR imaging can be explained by multiple factors. First, although faster imaging techniques have largely eliminated the need for sedation during imaging, fetal MR images are still frequently compromised by fetal motion. ${ }^{23}$ Second, differences in imaging techniques between pre- and postnatal imaging also contributed to low sensitivity. T2 single-shot fast spin-echo images are considered the workhorse of fetal MR imaging; however, the relative increased speed of imaging comes at the cost of decreased spatial resolution compared with the standard T2 FSE images used to image the brain postnatally. ${ }^{23-25}$ Although not yet well-studied, fetal MR imaging at 3T may improve spatial resolution through faster scanning times and a higher signal-to-noise ratio in future investigations. ${ }^{26}$ Third, the very small size of fetal neuroanatomy also contributes to the decreased sensitivity of detecting SEH on fetal MR imaging. Of note, GA at imaging did not appear to play a significant role in the accuracy of diagnosing SEH in our study. However, given that a large portion of the patients in our study were evaluated specifically for prenatal repair of a myelomeningocele, which is typically performed before 26 weeks' GA, this observation may not be generalizable. ${ }^{4}$

We also demonstrated a relatively low specificity in the diagnosis of SEH on fetal MR imaging, which is a little more difficult to explain. In our study, we looked at only patients with spinal dysraphisms, who have a much higher incidence of SEH than the general population and have other associated pathologies unique to the disease entity. ${ }^{7,27}$ The presence of ependymal nodularity on fetal MR imaging that does not correspond with SEH postnatally may potentially be explained by several factors. First, histologic studies in fetuses with open spinal dysraphisms have demonstrated neuroepithelial/ependymal denudation before the onset of hydrocephalus. ${ }^{28}$ Thus, it is possible that the ependymal nodularity we see on fetal MR imaging is a reflection of this ependymal denudation demonstrated on histologic studies. We also suspect that hydrocephalus plays a role. The pathology literature in infants describes ventricular dilation correlating with discontinuities in the ependymal lining along with ependymal cell loss. ${ }^{29}$ Histologic analysis of fetuses with hydrocephalus demonstrates loss of the germinal ependymal zone, disorganization of the subventricular zone, and abnormal migration of neuroblasts into the ventricular cavity. ${ }^{30}$ Since there has been a potential link described between hydrocephalus and SEH because denudation of the neuroepithelium may cause disruption of the neuronal migrational pathways, it is possible that the nodules we see prenatally represent delayed migration of neurons that migrate later in pregnancy. ${ }^{31}$ On the other hand, in the presence of hydrocephalus, it is conceivable that migrational anomalies may develop later in gestation and then be apparent in the postnatal period.

The configuration of the germinal matrix on fetal MR imaging in healthy fetuses has been well-described and can potentially be used as one of the many markers in evaluating fetal brain maturation. ${ }^{32}$ It is also possible that hydrocephalus in patients with spinal dysraphisms disrupts the normal development and configuration of the germinal matrix, causing the 
nodularity we see on fetal imaging. Of note, we did not appreciate any ependymal nodularity outside the SEH postnatally, which can be primarily explained by the relative absence of a germinal matrix. On the basis of our observations, we do not believe it is possible to differentiate SEH from ependymal irregularity related to other etiologies in fetuses with spinal dysraphism on MR imaging.

Our study adds to the current literature in many ways. First, it is one of the largest of its kind looking at this specific finding on fetal MR imaging, with direct comparison with the postnatal imaging findings. Second, given the increasing availability of prenatal repair of myelomeningoceles, studies examining the accuracy of MR imaging in the evaluation of the fetal brain are becoming essential. ${ }^{4-6}$ While there have been other studies that examined the sensitivity of fetal MR imaging in the diagnosis of SEH, this study is unique in that it reports the limited specificity and is the first to describe the appearance of ependymal nodularity on MR imaging in fetuses with spinal dysraphisms that does not correlate with SEH (or any other nodular periventricular/subependymal pathology) postnatally. ${ }^{17,22}$ On fetal MR imaging, the differential diagnosis for SEH includes tuberous sclerosis and subependymal hemorrhage. ${ }^{16}$ Our findings suggest that abnormal nodularity of the germinal matrix is another important differential consideration.

Our study has some limitations. First, this is a retrospective study limiting its internal validity. In addition, given that this is a single-institution study performed within a certain timeframe, the external validity may be limited as well. To acquire this number of patients for our study, we examined studies from a 10-year time span at our institution. These patients were scanned on different magnets and, because our scanners were upgraded multiple times over the years, minor differences in scanning parameters were used to optimize image quality, which may also affect our results.

\section{CONCLUSIONS}

Fetal MR imaging is limited in its ability to identify SEH in fetuses with spinal dysraphism. We believe that this limitation relates to a combination of factors: the sensitivity possibly compromised by artifacts from fetal motion, the very small size of fetal neuroanatomy, and the resolution of the fetal MR imaging technique. The specificity may be compromised by denudation of the ependyma and possibility irregularity of the germinal matrix by stretching of the developing ependyma/ subependyma in the presence of VMG.

\section{REFERENCES}

1. Sonigo PC, Rypens FF, Carteret M, et al. MR imaging of fetal cerebral anomalies. Pediatr Radiol 1998;28:212-22 CrossRef Medline

2. Kline-Fath BM, Calvo-Garcia MA. Prenatal imaging of congenital malformations of the brain. Semin Ultrasound CT MRI 2011;32: 167-88 CrossRef Medline

3. Glenn OA, Barkovich J. Magnetic resonance imaging of the fetal brain and spine: an increasingly important tool in prenatal diagnosis_part 2. AJNR Am J Neuroradiol 2006;27:1807-14 Medline

4. Adzick NS, Thom EA, Spong CY, et al; MOMS Investigators. A randomized trial of prenatal versus postnatal repair of myelomeningocele. N Engl J Med 2011;364:993-1004 CrossRef Medline

5. Saadai P, Farmer DL. Clinics in perinatology: fetal surgery for myelomeningocele. Clin Perinatol 2012;39:279-88
6. Sutton LN, Adzick NS, Bilaniuk LT, et al. Improvement in hindbrain herniation demonstrated by serial fetal magnetic resonance imaging following fetal surgery for myelomeningocele. JAMA 1999;282: 1826-31 CrossRef Medline

7. Hino-Shishikura A, Niwa T, Aida N, et al. Periventricular nodular heterotopia is related to severity of the hindbrain deformity in Chiari II malformation. Pediatr Radiol 2012;42:1212-17 CrossRef Medline

8. Barkovich A, Kjos B. Grey matter heterotopias: MR characteristics and correlation with developmental and neurologic manifestations. Radiology 1992;182:493-99 CrossRef Medline

9. Barkovich AJ, Kuzniecky RI. Gray matter heterotopia. Neurology 2000;55:1603-08 Medline

10. Zajac-Mnich M, Kostkiewicz A, Guz W, et al. Clinical and morphological aspects of gray matter heterotopia type developmental malformations. Polish J Radiol 2014;79:502-07 CrossRef Medline

11. Mandelstam SA, Leventer RJ, Sandow A, et al. Bilateral posterior periventricular nodular heterotopia: a recognizable cortical malformation with a spectrum of associated brain abnormalities. AJNR Am J Neuroradiol 2013;34:432-38 CrossRef Medline

12. González G, Vedolin L, Barry B, et al. Location of periventricular nodular heterotopia is related to the malformation phenotype on MRI. AJNR Am J Neuroradiol 2013;34:877-83 CrossRef Medline

13. Manganaro L, Saldari M, Bernardo S, et al. Bilateral subependymal heterotopia, ventriculomegaly and cerebellar asymmetry: fetal MRI findings of a rare association of brain anomalies. J Radiol Case Rep 2013;7:38-45 CrossRef Medline

14. Meoded A, Turan S, Harman C, et al. Pre- and postnatal ultrasound and magnetic resonance imaging of intracranial extra-axial glioneuronal heterotopia. Fetal Diagn Ther 2011;30:314-16 CrossRef Medline

15. Righini A, Zirpoli S, Mrakic F, et al. Early prenatal MR imaging diagnosis of polymicrogyria. AJNR Am J Neuroradiol 2004;25: 343-46 Medline

16. Mitchell LA, Simon EM, Filly RA, et al. Antenatal diagnosis of subependymal heterotopia. AJNR Am J Neuroradiol 2000;21:296-300 Medline

17. Glenn OA, Cuneo AA, Barkovich AJ, et al. Malformations of cortical development: diagnostic accuracy of fetal MR imaging. Radiology 2012;263:843-55 CrossRef Medline

18. Rufener SL, Ibrahim M, Raybaud CA, et al. Congenital spine and spinal cord malformations: pictorial review. Am J Roentgenol 2010; 194(3 suppl):S26-37 CrossRef Medline

19. Melchiorre $\mathrm{K}$, Bhide $\mathrm{A}$, Gika $\mathrm{AD}$, et al. Counseling in isolated mild fetal ventriculomegaly. Ultrasound Obstet Gynecol 2009;34:212-24 CrossRef Medline

20. Simon EM, Goldstein RB, Coakley FV, et al. Fast MR imaging of fetal CNS anomalies in utero. AJNR Am J Neuroradiol 2000;21:1688-98 Medline

21. Tang PH, Bartha AI, Norton ME, et al. Agenesis of the corpus callosum: an MR imaging analysis of associated abnormalities in the fetus. AJNR Am J Neuroradiol 2009;30:257-63 CrossRef Medline

22. Blondiaux E, Sileo C, Nahama-Allouche C, et al. Periventricular nodular heterotopia on prenatal ultrasound and magnetic resonance imaging. Ultrasound Obstet Gynecol 2013;42:149-55 CrossRef Medline

23. Prayer D, Brugger PC, Prayer L. Fetal MRI: techniques and protocols. Pediatr Radiol 2004;34:685-93 Medline

24. Dhouib A, Blondiaux E, Moutard ML, et al. Correlation between pre- and postnatal cerebral magnetic resonance imaging. Ultrasound Obstet Gynecol 2011;38:170-78 CrossRef Medline

25. Li T, Mirowitz SA. Fast multi-planar gradient echo MR imaging: impact of variation in pulse sequence parameters on image quality and artifacts. Magn Reson Imaging 2004;22:807-14 CrossRef Medline

26. Welsh RC, Nemec U, Thomason ME. Fetal magnetic resonance imaging at 3.0 T. Top Magn Reson Imaging 2011;22:119-31 CrossRef Medline 
27. Miller E, Widjaja E, Blaser S, et al. The old and the new: supratentorial MR findings in Chiari II malformation. Childs Nerv Syst 2008; 24:563-75 Medline

28. De Wit OA, den Dunnen WF, Sollie KM, et al. Pathogenesis of cerebral malformations in human fetuses with meningomyelocele. $\mathrm{Ce}$ rebrospinal Fluid Res 2008;5:4 CrossRef Medline

29. Del Bigio MR. Ependymal reactions to injury: a review. J Neuropathol Exp Neurol 1995;54:1-15 Medline

30. Domínguez-Pinos MD, Páez P, Jiménez AJ, et al. Ependymal denudation and alterations of the subventricular zone occur in human fetuses with a moderate communicating hydrocephalus. J Neuropathol Exp Neurol 2005;64:595-604 Medline

31. Ferland RJ, Batiz LF, Neal J, et al. Disruption of neural progenitors along the ventricular and subventricular zones in periventricular heterotopia. Hum Mol Genet 2009;18:497-516 CrossRef Medline

32. Vossough A, Limperopoulos C, Putt ME, et al. Development and validation of a semiquantitative brain maturation score on fetal MR images: initial results. Radiology 2013;268:200-07 CrossRef Medline 